\title{
POR QUE A URGÊNCIA DA REFORMA DO ENSINO MÉDIO? MEDIDA PROVISÓRIA No 746/2016 (LEI № 13.415/2017)*
}

\author{
VÂNia Cardoso da MotTa ${ }^{1}$ \\ GAUDÊNCIO FRIGOTTO ${ }^{2}$
}

\begin{abstract}
RESUMO: $\mathrm{O}$ artigo analisa o porquê da urgência da reforma do Ensino Médio proposta pela Medida Provisória no 746/2016, transformada na Lei $\mathrm{n}^{\circ}$ 13.415/2017, tendo em vista os "sujeitos dessa reforma" e o contexto de regressão da regressão teórica e política. Trata-se de uma pesquisa documental que adota a chave analítica da teoria social crítica, em especial de Gramsci e de Fernandes, inserida nos debates sobre trabalho-educação. Indicamos elementos para constatar que essa "reforma" expressa a contradição ético-política do pensamento e da moral capitalista do tipo dependente. Em seguida, buscamos evidenciar a estreita relação entre a Proposta de Emenda Constitucional no 55 , o Projeto de Lei no 867/2015 e a Medida Provisória no 746/2016 como um tríplice retrocesso na educação básica. Constatamos que tal "urgência" tem como pano de fundo a administração da "questáo social", negando os fundamentos das ciências que permitem aos jovens entender e dominar o funcionamento do mundo das coisas e da sociedade humana.
\end{abstract}

Palavras-chave: MP no 746/2016. Trabalho-educação. Capitalismo dependente. Questão social.

\section{WHY THE EMERGENCY OF REFORM OF HIGH SCHOOL? Provisional Measure n. 746/2016 (LAW N. 13.415/2017)}

ABSTRACT: The article analyzes the urgency of the high school reform proposed by the Provisional Measure n. 746/2016, transformed in the Law n. 13.415/2017, in view of the "subjects of this reform" and the context of regression of theoretical and political regression. It is a documentary research that adopts the analytical key of critical social theory, especially of Gramsci and Fernandes, inserted in the debates

\footnotetext{
*Pesquisa Educação na Rota do Desenvolvimento: investimento social privado em educaçáo nos arranjos de desenvolvimento da educação, financiada pelo Conselho Nacional de Desenvolvimento Científico e Tecnológico (CNPq) (Processo no 445525/2014-2).

${ }^{1}$ Universidade Federal do Rio de Janeiro, Faculdade de Educação, Programa de Pós-Graduaçáo em Educação - Rio de Janeiro (RJ), Brasil. E-mail: vaniacmotta@gmail.com

${ }^{2}$ Universidade do Estado do Rio de Janeiro, Programa de Pós-Graduação em Políticas Públicas e Formação Humana - Rio de Janeiro (RJ), Brasil. E-mail:gfrigotto@globo.com DOI: 10.1590/ES0101-73302017176606
} 
about work-education. We indicate elements to verify that this "reform" expresses the ethical-political contradiction of capitalist thinking and moral of the dependent type. Then we seek to show the close relationship between Constitucional Amendment n. 55, Bill n. 867/2015 and Provisional Measure n. 746/2016 (Law n. 13.415/2017) as a triple regression in basic education. We note that the so-called "urgency" has as its background the management of the "social question", denying the foundations of the sciences that allow young people to understand and master the work of the world of things and human society.

Keywords: MP n. 746/2016. Work-education. Dependent capitalism. Social question.

\section{POURQUOI L'URGENCE DE LA RÉFORME DE L'ÉCOLE SECONDAIRE ? LA MeSURE Provisoire N. 746/2016 (LOI N. 13.415/ 2017)}

RÉSUMÉ: Cet article analyse pourquoi l'urgence de la réforme de l'enseignement secondaire proposé par la Mesure Provisoire (MP) n. 746/2016, transformée dans la Loi n. 13.415/2017, compte tenu du "sujet de cette réforme " et le contexte de régression de la régression théorique et politique. Il s'agit d'une recherche documentaire qui adopte la clé analytique de la théorie sociale critique, surtout Gramsci et Fernandes, et qui fait partie des débats sur travail-éducation. On indique des éléments pour vérifier que cette " réforme " exprime la contradiction éthico-politique de la pensée et la morale capitaliste du type dépendant. Ensuite, on continue à chercher à mettre en évidence la relation étroite entre le Projet d'Amendement Constitutionnel n. 55, le Projet de Loi n. $867 / 2015$ et la MP n. 746/2016 comme un triple revers à l'éducation de base. On confirme que ladite " urgence " a comme toile de fond la gestion de la "question sociale ", en niant les fondements des sciences qui permettent aux jeunes de comprendre et de maîtriser la façon dont le monde matériel et de la société humaine fonctionnent.

Mots-clés: MP n. 746/2016. L'éducation professionnelle. Capitalisme dépendant. Question sociale.

\section{Introdução}

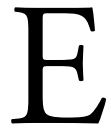

ste artigo analisa, em um escopo político mais amplo, o porquê da urgência da reforma do Ensino Médio proposta pela Medida Provisória (MP) no 746/2016, aprovada e transformada na Lei no 13.415 , de fevereiro de 2017. Buscamos elementos para compreender o que está posto de fundo nessa suposta urgência, tendo em vista os "sujeitos dessa reforma" e o contexto de regressão da regressão teórica e política que, para além das batutas neoliberais, foi 
orquestrada impositivamente. Trata-se de uma pesquisa documental que adota a chave analítica da teoria social crítica, em especial de Antônio Gramsci e Florestan Fernandes, inserida nos debates sobre trabalho-educação.

Partimos do pressuposto de que essa "reforma" imprime, sem reservas ou busca de consenso, a insanável contradição ético-política do pensamento e da moral capitalista do tipo dependente: perversamente autoritário. Imbuída do caráter ideológico instrumental, esta é conduzida como processo natural de modernização - fetichizada pelo determinismo tecnológico-inovador —, despida de relaçóes de poder e sem historicidade. Ou seja, a história de luta voltada para a supressão do dualismo estrutural do Ensino Médio foi rasgada; não há sujeitos históricos, e sim alunos abstratos, jovens trabalhadores deslocados de suas condiçôes objetivas e materiais reais.

No entanto, a realidade concreta afronta essa visão autoritária e instrumental. Os sujeitos dessa história enfrentam diariamente as duras barricadas e trincheiras postas pelas fraçóes dominantes, como as que ocorreram na Jornada de Junho de 2013, nos movimentos de ocupaçôes das escolas e universidades, nas manifestações dos funcionários públicos do Rio de Janeiro em frente à Assembleia Legislativa do Rio de Janeiro (Alerj) e muitas outras contra os encaminhamentos políticos de austeridade econômica e supressão dos direitos sociais.

O objetivo deste texto foi, em um primeiro ponto, explicitar as razóes ideológicas do porquê da urgência da reforma do Ensino Médio e como tais razóes se desmentem no confronto com a realidade da educaçáo pública; foi mostrar que se trata de uma "reforma" contra a maioria dos jovens - cerca de $85 \%$ dos que frequentam a escola pública - , cujo objetivo é administrar a "questão social", condenando geraçóes ao trabalho simples. Em um segundo ponto, buscamos brevemente evidenciar a estreita relaçâo entre a Proposta de Emenda Constitucional (PEC) no 55, o Projeto de Lei (PL) no 867/2015 e a MP no 746/2016 (Lei no 13.415/2017). Como consideração final, destacamos que se trata de uma reforma contra os filhos da classe trabalhadora, negando-lhes o conhecimento necessário ao trabalho complexo e à autonomia de pensamento para lutar por seus direitos.

\section{Por que a reforma do Ensino Médio é urgente?}

Segundo dirigentes do Ministério da Educação (MEC), a reforma do Ensino Médio é urgente porque é necessário destravar as barreiras que impedem o crescimento econômico. E a educação, principalmente a educação profissional, é um fator importante para a retomada do crescimento econômico, uma vez que o investimento em capital humano potencializa a produtividade. Nessa perspectiva, no âmbito da educação, seriam aspectos necessários para elevar as condições de competitividade do Brasil no mercado internacional: o investimento na melhoria da 
qualidade do Ensino Médio, até mesmo com o aumento da jornada escolar, visando melhores alcances no desempenho escolar; a reestruturação do currículo, ajustando-o às mudanças no mundo do trabalho, em conformidade com a suposta educaçáo do século XXI; a ampliação do número de vagas; e a contenção da evasão escolar.

Sintetizando, as questóes-chave da MP no 746/2016 (Lei $\mathrm{n}^{\circ}$ 13.415/2017) são: investir no capital humano visando maior produtividade; modernizar a estrutura curricular, flexibilizando por áreas de conhecimento; e melhorar os resultados do desempenho escolar. Nesta parte, discorreremos sobre essas questôes, tentando responder o porquê da urgência da "reforma", tendo em vista os "sujeitos dessa etapa educacional" (BRASIL, 2013b, p. 148).

\section{Investimento em capital humano}

A ideia de investimento em capital humano como motor de desenvolvimento econômico é uma determinada concepção de formação humana nos marcos restritos das necessidades de mercado. Enfatiza os conhecimentos úteis que o estudante deve adquirir para impulsionar a produtividade dos setores econômicos, a fim de potencializar a competitividade nos mercados local e internacional, ou para criar condições de empregabilidade, isto é, desenvolver habilidades e competências que potencializem a inserção do indivíduo no mercado de trabalho. A formaçáo humana é diretamente articulada com a formaçáo da força de trabalho, sendo esta considerada um dos fatores de produção, assim como o maquinário. Trata-se de uma concepção predominante na história da educação brasileira, legitimada em políticas públicas de educação em diferentes momentos dos ciclos do capital. No caso brasileiro, no período nacional-desenvolvimentista, difundia-se a necessidade de investir no capital humano, articulado ao projeto de modernização da nação, como um mecanismo para avançar etapas de desenvolvimento econômico e social; no atual ciclo de globalização neoliberal, esse investimento é justificado pelo aumento da competitividade no mercado internacional e para gerar condiçốes de empregabilidade.

No ciclo da globalização neoliberal, a política econômica está focada nas vantagens comparativas ${ }^{1}$ dos países como forma de potencializar a competitividade na nova divisão internacional do trabalho. No Brasil, as vantagens comparativas são: os fartos recursos naturais que possibilitam o mercado de exportação de matérias-primas; e o setor de serviços, que é favorecido, ainda, pelo baixo valor da mercadoria força de trabalho. Com isso, na nova divisão internacional do trabalho, a base econômica brasileira manteve-se na produção e exportação de commodities minerais, agrícolas e alguns produtos manufaturados; ${ }^{2}$ e o baixo valor da mercadoria força de trabalho atraiu muitas indústrias estrangeiras para produzirem determinados segmentos do processo produtivo, como as montadoras de automóveis e motocicletas. São setores produtivos de baixo valor tecnológico 
agregado, o que não demanda um montante significativo de força de trabalho para o trabalho complexo.

Segundo Pochmann (2011), a base da pirâmide social é formada por trabalhadores vinculados ao setor terciário, de serviços e de comércio, predominando ocupaçóes informais, de baixa qualificação e baixo valor de remuneraçáo. E, constata Barroso (2016, p. 9), "olhando-se de 1980 para cá, a participação da indústria no PIB caiu de $28 \%$ para $9 \%$ " e há uma estimativa de que esta participação chegue ao "nível semelhante ao de meados de 1950" (BARROSO, 2016, p. 9); enquanto "o setor de serviços já alcança cerca de 60\% da mão-de-obra ocupada" (BARROSO, 2016, p. 9). Outra especificidade brasileira é o quantitativo de micro e pequenas empresas: dados do Serviço Brasileiro de Apoio às Micros e Pequenas Empresas (SEBRAE) indicam que elas representam 98,5\% do total de empresas no Brasil.

Para refletirmos sobre as contradiçóes da ideologia do capital humano, em vista ao perfil da base econômica brasileira, destacamos um trecho do documento do MEC sobre as Diretrizes Curriculares Nacionais para o Ensino Médio (DCNEM) (BRASIL, 2013b), que expressa essa relação orgânica entre educação e economia.

Para alcançar o pleno desenvolvimento, o Brasil precisa investir fortemente na ampliação de sua capacidade tecnológica e na formação de profissionais de nível médio e superior. Hoje, vários setores industriais e de serviços não se expandem na intensidade e ritmos adequados ao novo papel que o Brasil desempenha no cenário mundial, por se ressentirem da falta desses profissionais. Sem uma sólida expansão do Ensino Médio com qualidade, por outro lado, não se conseguirá que nossas universidades e centros tecnológicos atinjam o grau de excelência necessário para que o País dê o grande salto para o futuro (BRASIL, 2013b, p. 146).

A tese de "alcançar o pleno desenvolvimento" investindo em "capacidade tecnológica" e na formação da força de trabalho com maior qualificação contradiz a longa história de baixo investimento na educação brasileira. Como também a predominância de políticas econômicas que reforçam o desenvolvimento dependente, subordinado aos mercados internacionais, que caracteriza a constituição do nosso tipo de capitalismo. Justificar que os setores econômicos não se expandem por se "ressentirem da falta" de profissionais qualificados não corresponde com a realidade, pois nos curtos momentos de expansão do capital brasileiro a força de trabalho demandada foi para o trabalho simples.

Pochmann (2011) analisou o período entre 1960 e 2010, buscando identificar as "mudanças recentes na renda e na estrutura ocupacional brasileiras" - parte do título da pesquisa - associadas às transformaçóes na estrutura produtiva. Aponta que entre 2004 e 2010 houve elevaçáo da renda per capita e redução da desigualdade, inclusive devido aos programas sociais direcionados às camadas mais pobres da população. $\mathrm{O}$ impulso do setor terciário (comércio 
e serviços) gerou novos postos de trabalho; no entanto, concentrou-se naqueles de salário base. $\mathrm{O}$ mesmo ocorreu com o setor secundário (indústria, incluindo a construção civil): os novos postos de trabalho situaram-se na base da pirâmide. Também percebeu-se um aumento da importância do setor terciário, em razão de seu peso relativo ao produto interno bruto (PIB). Todavia, conclui o autor, nos diferentes setores econômicos predominaram as atividades de baixo valor agregado, com remuneraçôes próximas ao salário mínimo.

Do nosso ponto de vista, avançar tecnologicamente e qualificar a força de trabalho exigem alterar a posição subordinada e dependente do Brasil na divisão internacional do trabalho. Algo que se distancia cada vez mais, principalmente com as últimas medidas austeras de contenção de despesas e priorização do pagamento de juros e amortização da dívida (superávit primário) ${ }^{3}$ em detrimento de investimentos sociais.

Então, qual seria, de fato, a urgência da reforma do Ensino Médio diante de um cenário político-econômico de austeridade, em meio a cortes profundos no orçamento da educaçáo, saúde, cultura, seguridade, cuja base econômica de baixo valor tecnológico agregado e alto índice de informalidade não necessitam de uma força de trabalho para atividades complexas?

Citando mais um trecho do documento supramencionado (BRASIL, 2013b), observemos agora dados do Instituto Brasileiro de Geografia e Estatística (IBGE) de 2010.

\begin{abstract}
De acordo com o documento "Síntese dos Indicadores Sociais do IBGE: uma análise das condiçóes de vida da população brasileira" (IBGE, 2010), constata-se que a taxa de frequência bruta às escolas dos adolescentes de 15 a 17 anos é de 85,2\%. Já a taxa de escolarização líquida dos mesmos adolescentes (de 15 a 17 anos) é de 50,9\%. Isso significa dizer que metade dos adolescentes de 15 a 17 anos ainda não está matriculada no Ensino Médio (BRASIL, 2013b, p.149).
\end{abstract}

Seis anos depois houve uma melhoria nesses dados. No Censo Escolar 2012 foi confirmada a trajetória de expansão da matrícula na educação profissional, que em 2007 era de 780.162 e atingiu, em 2012, 1.362.200 matrículas, crescimento de 74,6\% no período (BRASIL, 2013a). Porém, provavelmente, o Programa Nacional de Acesso ao Ensino Técnico e Emprego (Pronatec), promulgado pela Lei no $12.513 / 2011$, foi o responsável por esse aumento de matrículas, já que foi anunciado com a oferta de oito milhôes de vagas. O Pronatec investe em dois tipos de formação: formação inicial e continuada (FIC) e cursos técnicos em nível médio. Sendo que "a maior parte das vagas, 1,6 milhão, cerca de $80 \%$, para a primeira modalidade, enquanto que para cursos técnicos estão previstas apenas 372 mil vagas" (JUNIA, 2016). 
Em levantamento realizado em julho de 2015 (não publicado), constatamos que a União transferiu recursos para o programa, em 2014, no montante de $\mathrm{R} \$ 2.648 .668 .385,35$, sendo que $\mathrm{R} \$ 2.581 .208 .152,00$ foram destinados ao Sistema S. Até junho de 2015, em meio aos cortes na educação, tinham sido transferidos para o Pronatec R \$ 551.413.899,65 e, desse montante, $\mathrm{R} \$$ 518.393.229,20 foram destinados ao Sistema $S^{4}$. Além da quase totalidade dos recursos públicos voltados para o "Ensino Técnico e ao emprego" — parte da sigla do programa - ter sido destinada ao setor privado, os cursos ofertados foram focados na FIC, isto é, em cursos de curta duração e voltados para o trabalho simples ofertados pelo Sistema $S$.

Enfim, a realidade concreta demonstra que a difusão da necessidade de investir em capital humano como motor de desenvolvimento econômico e social é uma ideologia, parcial e artificiosa. Os cortes no orçamento da educação e os repasses de recursos públicos para setores privados ofertarem cursos aligeirados e de baixo valor tecnológico agregado váo de encontro à ideologia do capital humano. Permanece, então, a questão de compreender as razóes da urgência de reformar o Ensino Médio com a justificativa da modernização da estrutura curricular flexibilização por áreas de conhecimento.

\section{Reestruturação do Ensino Médio: quem são os sujeitos dessa reforma?}

$\mathrm{Na}$ visão dos reformadores, a modernização do currículo do Ensino Médio busca alterar o currículo sobrecarregado de disciplinas "inúteis" ou "desinteressantes", ou seja, pouco atraentes aos jovens, o que justifica a grande evasão nesse nível de escolaridade.

Nessa perspectiva, são apontadas duas requisições:

1. A melhoria do ensino, tendo como referencial os critérios de qualidade definidos pela Organizaçáo de Cooperaçáo para o Desenvolvimento Econômico (OCDE), por meio do Programa Internacional de Avaliação de Estudantes (PISA), e os sistemas de avaliação nacional e estaduais, tais como o Índice de Desenvolvimento da Educação (IDEB), baseados nos mesmos critérios: português, matemática e, recentemente, ciências;

2. A modernização do Ensino Médio, no sentido de flexibilizar o currículo por áreas de conhecimento, voltando-se para as aptidóes dos alunos e das unidades escolares.

A MP no 746/2016 (Lei no 13.415/2017) promove a reestruturação do currículo do Ensino Médio em duas etapas: uma composta pela Base Nacional 
Comum Curricular (BNCC), que ainda está finalizando as discussōes; e a outra enfatizando as áreas de linguagens, matemática, ciências da natureza, ciências humanas e formação técnica e profissional, a ser implementada, progressivamente, em tempo integral. Trata-se de uma visão que já vinha sendo gestada em governos anteriores, como veremos adiante.

Para dar continuidade à nossa análise, retomamos o documento das DCNEM (BRASIL, 2013b), que afirma que as mudanças no currículo do Ensino Médio é de "interesse dos adolescentes e jovens, sujeitos dessa etapa educacional" (BRASIL, 2013b, p. 148, grifo nosso).

Mas quem são os "sujeitos dessa etapa educacional"?

Antes é importante destacar que, de acordo com a Pesquisa Nacional por Amostra de Domicílios (BRASIL, 2012), os jovens com até 29 anos de idade representam $48,6 \%$ dos brasileiros ${ }^{5}$, ou seja, pouco menos da metade da populaçẫo brasileira é composta por jovens.

Retomando a questão da reforma do Ensino Médio, esta abarca as redes privada e pública, regulares e de educaçáo profissional. A grande maioria dos estudantes do Ensino Médio é atendida na rede pública e, provavelmente, oriunda da rede pública. Conforme documento do MEC (BRASIL, 2015a), em 2014, do total de 49.771.371 matrículas na educação básica, $40.680 .590(81,7 \%)$ eram da rede pública.

Especificamente no Ensino Médio, o referido documento indica que, nas redes públicas, 7.229.831 matrículas foram realizadas, sendo 146.613 alunos matriculados na rede federal; 7.026.734, nas redes estaduais; e 56.489, nas redes municipais. Na rede privada, por sua vez, foram 1.070.358 estudantes. Ainda segundo o Censo Escolar Inep (Instituto Nacional de Estudos e Pesquisas) 2015 (BRASIL, 2016), estavam matriculados no Ensino Médio regular nas redes estaduais urbanas e rurais 6.459 .859 alunos, o que indica que, também no Ensino Médio, os estudantes brasileiros estão na rede pública de ensino. Entretanto, segundo PNAD-IBGE (BRASIL, 2015b), somente 56,7\% desses jovens, com idade até 19 anos, concluíram o Ensino Médio. Esses dados constatam que os "sujeitos dessa etapa educacional", logo, dessa reforma do Ensino Médio, são jovens oriundos das camadas populares. Outro aspecto importante é sobre a questáo do mercado de trabalho. Ainda que esses jovens vençam o gargalo da passagem do Ensino Fundamental para o Ensino Médio e concluam o Ensino Médio profissional, passam a compor a amarga estatística da maior taxa de desemprego ${ }^{6}$. A falácia de estimular o Ensino Médio para qualificar para o trabalho depara-se com a falta de emprego no mercado de trabalho para a quase totalidade desses jovens.

Ainda tentando reconhecer quem são os "sujeitos dessa etapa educacional", consideramos importante ressaltar que esse nível de ensino é composto por 
diferentes ofertas de cursos, em tempo parcial ou integral; com formação profissional ou não; ou em parcerias público-privadas. Nelas, teremos cursos técnicos em tempo integral e integrado aos conteúdos do Ensino Médio regular, como é o caso dos institutos e centros federal e estaduais de educação técnico-tecnológica; dos colégios com parcerias público-privadas, muitas voltadas para a formação da força de trabalho específica da empresa parceira ${ }^{7}$; dos colégios que ofertam o Ensino Médio regular, com currículos escolares diferenciados, como a proposta do Ensino Médio Inovador, que cria a possibilidade de "escolha pelo aluno do seu percurso formativo" e algumas turmas de aceleração da aprendizagem, visando corrigir o fluxo idade-série, também em parcerias público-privadas ${ }^{8}$; outros, principalmente colégios localizados em áreas violentas, de extrema pobreza e de "vulnerabilidade social" ou de "risco social", muitos em parcerias, ofertam cursos profissionalizantes mais simples, educação para o empreendedorismo, atividades de reforço escolar contra turno'; e, mais recentemente, vem sendo divulgada a necessidade de desenvolver competências e habilidades socioemocionais, a exemplo da parceria público-privada entre o Instituto Ayrton Senna (IAS) e a rede estadual do Rio de Janeiro ${ }^{10}$.

Como vimos, dos 7.229.831 alunos matriculados no Ensino Médio das redes públicas, 7.026.734 estão nas redes estaduais, o que significa que, a exemplo da rede estadual de ensino do Rio de Janeiro, estáo distribuídos nessas diferentes propostas de ensino. E como para ingressar em uma escola que possui parceria público-privada ou em um colégio de formação técnico-tecnológica o jovem precisa passar por um processo seletivo, podemos deduzir que grande parte desses alunos encontra-se no Ensino Médio regular, porém com o currículo escolar redesenhado, por meio de projetos alternativos que visam reduzir as taxas de reprovação, evasão e, ainda, regular a distorção idade/série educacional entre jovens da mesma idade.

Então, tendo em vista os "sujeitos dessa etapa educacional", a urgência da reforma do Ensino Médio, da "educação para o século XXI", não seria um mecanismo para administrar a "questâo social"?

Compreendemos "questão social", na perspectiva da teoria social crítica, como parte constitutiva das relaçôes sociais capitalistas, indissociável das configuraçôes assumidas pelo capital-trabalho e pelas expressóes ampliadas das desigualdades sociais, imprimindo relaçóes de poder. A teoria social crítica contrapóe a concepção conservadora de que a "questão social" e suas expressões - pobreza, desigualdade social, desemprego, etc. — são fenômenos autônomos, de responsabilidade individual ou coletiva ou governamental, e que, com isso, poderiam ser corrigidos, também, por açôes individuais ou coletivas ou amenizados por meio de políticas públicas focadas na camada mais "vulnerável" da população.

A definição de Iamamoto $(2004$, p. 11) deixa claro o caráter político da "questão social", explicando que esta surge a partir da preocupação de um deter- 
minado setor da sociedade que via na pobreza acentuada e generalizada - no pauperismo - advinda do processo de industrializaçáo, da "nova ordem", o risco ou a "ameaça de fratura" das instituiçóes sociais existentes, tendo em vista o ingresso da classe operária no cenário político. A contradição fundante do sistema capital que precisa ser permanentemente administrada, pois póe em risco a "coesão social". Hayek (1985) sugere a seguridade social focada. Para ele, não é problema o Estado garantir uma proteção contra privações sob a forma de renda mínima. Esse tipo de garantia ou "seguro contra extremo infortúnio pode ser do interesse de todos" (HAYEK, 1985, p. 109).

Organismos multilaterais internacionais são atuantes no papel de administrar a pobreza e, desde os anos 1980, vêm sugerindo aos países mais pobres que implementem políticas públicas sociais focadas e relacionadas à escolaridade (MOTTA, 2012). Em relatórios recentes do Banco Mundial, por exemplo, a educação ganha centralidade, não somente para a formação da força de trabalho, mas, principalmente, como mecanismo de redução da pobreza e das desigualdades (BIRD, 2016). No relatório "Estratégia 2020 para a Educação - Aprendizagem para Todos" (BIRD, 2011), o grupo Banco Mundial indica que sua prioridade no âmbito da educação é "ter os pobres e vulneráveis como objetivo, criar oportunidades de crescimento, promover acçóes colectivas globais e governaçáo" (BIRD, 2011, p. 3). E no Relatório de 2016 (BIRD, 2016), após analisar a recente crise econômica brasileira, o Banco Mundial aponta preocupação com "os 40\% mais pobres da população brasileira (B40, do inglês, Bottom 40)" (BIRD, 2016, p. v); e sugere "políticas que ampliem as oportunidades econômicas, aprimorem o capital humano e a resiliência e reconheçam os ativos dos pobres" (BIRD, 2016, p. v). Recentemente, a Comissão de Trabalho e a Comissão de Seguridade Social e Família da Câmara dos Deputados aprovaram o substitutivo de um projeto de lei que define os públicos prioritários para o Pronatec: "[...] mulheres vítimas de violência [...]; emigrantes brasileiros [...]; adolescentes [...] que participem dos Serviços de Acolhimento Institucional, em República ou em Família Acolhedora” (REVISTA POLI, 2016, p. 5).

Consensualmente, os organismos multilaterais, internacionais e regionais difundem a ideia de que os pobres atravancam o crescimento econômico, pois podem criar instabilidades políticas que afetam as boas condiçóes de acumulação do capital. Mas também entendem que os pobres têm algum potencial produtivo, e que este está sendo desperdiçado. Conforme expressa a equipe do Banco Mundial (2004 apud MOTTA, 2011, p. 133) ${ }^{11}$ : "a exclusão de grandes segmentos da sociedade desperdiça recursos potencialmente produtivos e gera conflito social".

Provavelmente, essa visão consensual explica a atuação da OCDE no âmbito da educação. Defendendo a relação orgânica entre educação, crescimento econômico e desenvolvimento social, esse organismo passou a controlar o 
desempenho escolar em nível internacional e, com ele, definir qualidade de educação: ler, escrever, contar e ter noções básicas de ciências. O PISA e, no caso do Brasil, o IDEB passaram a ser instrumentos de definição de qualidade, o que na perspectiva crítica não pode servir de parâmetro de qualidade de ensino. É nessa seara que a reestruturação do currículo do Ensino Médio é posta como urgente: melhorar o desempenho no IDEB e no PISA, flexibilizando o currículo de forma a facilitar as escolhas das disciplinas que os jovens das classes populares teriam menor dificuldade e, com isso, provavelmente, melhor desempenho nas avaliaçôes em larga escala; desenvolver habilidades e competências que facilitem o ingresso no mercado de trabalho, formal ou informal, ou que proporcionem ocupações que venham a gerar renda - nesse caso, por meio do ensino de empreendedorismo.

O momento brasileiro é de uma crise aguda que insere medidas econômicas e políticas ofensivas que afetam fundamentalmente nossos muitos milhares de jovens da classe trabalhadora. $\mathrm{E}$ as Jornadas de Junho e as ocupaçōes das escolas e universidades públicas indicam que irrompeu a luta de classes. Com isso, as burguesias dominantes asseveram os mecanismos de controle social por meio dos vários aparelhos do Estado em "união pessoal" com seus respectivos aparelhos privados de hegemonia e com organismos internacionais, introduzem um conjunto de políticas públicas que conformam a conjuntura (como veremos em seguida) e buscam cimentar a ideologia necessária para se consolidarem no poder e salvaguardarem os ganhos do capital. Por esse motivo, torna-se determinante introduzir reformas na educaçáo — ressaltamos, pública —, na qual se situa a grande massa de jovens da classe trabalhadora para administrar a "questão social" e criar as condições favoráveis para a expansão do capital.

\section{A relação entre a Proposta de Emenda Constitucional 55, o Projeto de Lei $n^{\circ}$ 867/2015 e a Medida Provisória $n^{\circ}$ 746/2016 (Lei no 13.415/2017): o tríplice retrocesso na educação básica}

Ditaduras e golpes em nossa história sempre ocorreram visando salvaguardar os ganhos do capital — que "não tem pátria", até o momento que interessa; na atualidade, esses movimentos focam especialmente o capital financeiro - que não produz uma cenoura - $\mathrm{e}$, correlatamente, por meio da retirada dos direitos da classe trabalhadora. O golpe que se consumou em 31 de agosto de 2016 tem, em comum aos demais, os interesses do capital, o apoio da mídia empresarial, o suporte do judiciário e o apelo moral, arma reiterada de manipulaçáo da grande massa a quem se negou sistematicamente o conhecimento escolar básico.

No entanto, consideramos que o atual golpe é mais profundo pelo fato de que a classe burguesa brasileira já não precisou das forças armadas para seu 
intento. Ao longo das últimas décadas organizou-se organicamente como classe na defesa dos interesses maiores e estruturou-se em todas as esferas do Estado Parlamento, Ministério Público, parte ativa do poder judiciário em seu órgão máximo e na burocracia do Estado. No âmbito da sociedade civil, as fraçóes burguesas dominantes ampliaram suas organizaçóes privadas - aparelhos de luta hegemônica da classe dominante - e intensificaram as disputas do projeto de sociedade e educação, aparelhos esses que, no núcleo duro, se expressam nos 14 grupos econômicos fundadores - denominados mantenedores - do movimento "Todos pela Educação" e das 18 organizaçóes que aparecem como parceiras. Colocamos "Todos pela Educaçáo" entre aspas, pois a sutil mudança do ideário da Organização das Naçóes Unidas para a Educação, a Ciência e a Cultura (UNESCO), "Educação para Todos", pode ser interpretada como "todos pela educação", que convém ao mercado e ao capital.

Não por acaso, o Movimento Escola "sem" Partido começou em 2004 e o Todos pela Educação, em 2005 - ainda que oficializado em 2006, demonstrou sua força com a deflagração do Plano de Desenvolvimento da Educação decretado pelo MEC com o nome Compromisso Todos pela Educação (Decreto n ${ }^{\circ}$ 6.094/2007). Também colocamos "sem" partido entre aspas, pois, na verdade, trata-se do partido único do capital, do mercado e do ódio ao pensamento crítico (FRIGOTTO, 2017). Embora os governos de Luiz Inácio Lula da Silva e Dilma Rousseff tenham efetivamente alterado de maneira positiva o salário mínimo, com isso, oportunizado uma pequena distribuição de renda, promoveram políticas de inclusão ao alimento, à escola, à universidade e à casa própria e, ainda, uma política externa diferenciada. Essas mudanças importantes foram feitas sem confrontar a minoria prepotente, referida por Florestan Fernandes. Ou seja, a lição não foi aprendida. E em um contexto de crise de ganhos do capital no mundo, os interesses internos e externos juntaram-se e consumaram o golpe antidemocrático das frações burguesas dominantes.

A PEC no 55, aprovada no Congresso Nacional, representa, sem dúvida, as forças sociais que golpearam a democracia brasileira e constitui-se na maior agressão às conquistas de direitos da classe trabalhadora desde o fim da escravidão. Liquida o Estado brasileiro como agente de garantia de direitos universais, dos quais se destacam o trabalho, a educação, a saúde e a habitação. Uma medida que confirma os argumentos da "urgência" da reforma do Ensino Médio, pois não só o inviabiliza como educação básica de qualidade, como o privatiza por dentro. Assim como vai acabar de privatizar, por mecanismos diversos, as universidades públicas.

O caráter desumano e criminoso da PEC no 55 é que, ao congelar por 20 anos o investimento público na área social, reserva toda a riqueza produzida para ganhos do capital, em especial mediante juros criminosos acobertados por leis injustas. Leis e Justiça têm caminhado em sentido oposto aos interesses da 
classe trabalhadora e de forma aberta. Portanto, uma medida que vai contra a vida digna e, como tal, de forma mediata representa a morte, pelo desemprego estrutural e crescente, dos jovens "condenados do sistema" (FERNANDES, 1981), em especial, as geraçôes de jovens presas fáceis do ilícito e que acabam esquartejados nos presídios brasileiros, na forma de campos de concentração.

O movimento do Escola "sem" Partido, que busca consolidar-se em lei pelo PL no $867 / 2015$, expressa o pensamento do ódio, transigência que tem similitude como as teses do nazismo e do fascismo. Esse é o lado oculto e mais letal cujo preço será brutal caso se transforme em lei. O ódio a Paulo Freire, educador cuja tese básica da relaçấo pedagógica é o diálogo, indica o caráter totalitário e desagregador do Escola "sem" partido. Além disso, essa é a face ideológica do Todos pela Educação, cujos integrantes e apoiadores vêm desclassificando a escola e a universidade públicas e combatendo o pensamento crítico desde a década de 1990.

É uma constante nas ditaduras e golpes efetivarem reformas na educação. Assim foi na ditadura Vargas, na ditadura empresarial-militar de 1964, no golpe neoliberal na década de 1990 à Constituição Federal e, agora, no golpe parlamentar, midiático, jurídico e policial. A reforma do Ensino Médio e o congelamento dos investimentos nas instituiçóes públicas de Ensino Superior são a concretização material do que interessa à PEC no 55 e vai ao encontro das ideologias do Escola "sem" Partido e do Todos pela Educação.

Com efeito, o que postulam, na verdade, é a surrada tese do conhecimento e do ensinar na perspectiva tecnicista que autodenomina sua ideologia, concepção de conhecimento, educação e escola como neutros.

A reforma por MP, sem debate e "sem sociedade", na verdade se deve, em grande medida, ao medo de que a luta exemplar dos estudantes secundaristas nas ocupaçóes e de outros movimentos se amplie. E certamente se ampliará quando alunos, pais e cidadãos de bom senso perceberem que a reforma do Ensino Médio é uma traição às geraçôes atuais e futuras, interditando seu futuro. A reforma do Ensino Médio, protagonizada pelos arautos do Golpe de Estado consumado no dia 31 de agosto de 2016, condensa um tríplice retrocesso e de forma pior:

- retroage à Reforma Capanema no contexto da ditadura Vargas, onde o ensino secundário industrial, comercial e agrícola não tinha equivalência para o ingresso no Ensino Superior. A superação definitiva deu-se mediante a Lei no 4.024/1961, que instaurou a equivalência dos diferentes ramos do então ensino industrial, agrícola e comercial. Agora com o engodo de que o aluno tem alternativas de escolha, a lei cria cinco itinerários estanques que supostamente seriam oferecidos pelas escolas. Amplia-se, agora, o leque da não equivalência; 
- retroage à Lei no 5.692/1971, reforma da educaçáo dos tempos da ditadura empresarial militar com uma profissionalização precária frente às realidades dos estados. Não será questão de "livre escolha", como propalam os reformadores, mas compulsória, pois será o caminho de cumprir com a carga horária obrigatória e, quando houver, a ampliação do que denomina de escola de tempo integral em condições infraestruturais precarizadas ${ }^{12}$. Nessas condiçóes dadas, cada escola vai ofertar a educação profissional que couber em seu orçamento;

- retoma, em um outro contexto e dentro de um estado de exceçáo, o ideário da política de Paulo Renato de Souza. Agora sequer precisam postergar as medidas, como ocorreu com a Lei de Diretrizes e Bases da Educação Nacional (LDB) no 9.394/1996. Retoma, de forma pior, o Decreto no 2.208/1996, que já aprofundava a dualidade estrutural entre educação profissional e educação básica. $\mathrm{O}$ anúncio do MedioTec pelo MEC indica, de forma clara, a incorporação do Pronatec no Ensino Médio regular. Uma comprovação inequívoca de que se trata de uma contrarreforma destinada aos filhos da classe trabalhadora. Também uma confissão explícita de que o MEC assume, de fato, uma divisão classista da educação.

Quem comanda a contrarreforma não é Paulo Renato de Souza, pois já não vive, mas a sua mais fiel escudeira Maria Helena Guimarães de Castro, hoje Secretária Geral do MEC que, na prática, dirige o golpe de Estado na educação.

\section{A título de considerações finais}

A conclusão clara é que a contrarreforma do Ensino Médio por imposição autoritária de MP é congruente e necessária para sustentar violência da PEC $\mathrm{n}^{\mathrm{o}} 55$, que expressa o desmanche dos direitos universais da classe trabalhadora mediante o congelamento dos recursos públicos para a educação, saúde, cultura, etc. "Reforma" que traduz, na prática, o ideário liberal-conservador no qual convergem elementos fascistas do movimento Escola "sem" Partido e economicistas do Todos pela Educação, revestidos pelas benesses da filantropia dos homens de bem e propulsores do desenvolvimento econômico. Apresenta rigidez no tocante à implementação das disciplinas recomendadas pelos organismos internacionais, intelectuais coletivos e orgânicos do capital e do mercado e na negaçáo tácita do conhecimento básico para uma leitura autônoma da realidade social, esta acobertada pela delegação da "livre escolha" do jovem dentre as opções ofertadas.

A segunda conclusão, derivada da primeira, é de que a MP no 746/2016 (Lei no $13.415 / 2017$ ) liquida com o Ensino Médio como etapa final da educação 
básica, confronta a Constituição e anula a LDB e o Plano Nacional de Educação (PNE). Embora ambos tenham sido retalhados pelas forças do capital, no embate e na luta preservavam conquistas ampliadas para os filhos da classe trabalhadora que, em sua grande maioria, frequentam o ensino público.

Por permitir a contratação de supostos especialistas, porém não licenciados, como professores, essa "reforma" desobriga ou força os estados a não realizarem concursos públicos. Permite, como o caso atual do estado do Rio de Janeiro e que deve ser o modelo geral, que os estados se enquadrem na mordaça da austeridade às custas de cortes de salários e aposentadorias, aumento da contribuição da Previdência e flexibilização, ainda maior, das leis trabalhistas. Com o corolário, afirmam-se as parcerias público-privadas como estratégia de privatização do Ensino Médio pela venda de pacotes e determinaçáo do conteúdo e dos métodos de ensino por institutos privados ou organizaçóes sociais, supostamente neutros.

Como conclusão mais geral, trata-se de uma contrarreforma que expressa e consolida o projeto da classe dominante brasileira em sua marca antinacional, antipovo, antieducação pública, em suas bases político-econômicas de capitalismo dependente, desenvolvimento desigual e combinado, que condena geraçôes ao trabalho simples e nega os fundamentos das ciências que permitem aos jovens entender e dominar como funciona o mundo das coisas e a sociedade humana. Uma violência cínica de interdição do futuro dos filhos da classe trabalhadora por meio da oficialização da dualidade intensificada do Ensino Médio e de uma escola esvaziada, na perspectiva de Antonio Gramsci.

Pelo grau de violência e pelo que interdita, uma contrarreforma que tem que ser confrontada, sem tréguas, no todo e nos detalhes.

\section{Notas}

1. Trata-se da clássica tese que defende a especialização em determinadas atividades econômicas como princípio motivador da competitividade das nações no contexto do livre-comércio internacional.

2. Fontes: IBGE, Ministério de Minas e Energias, Banco Mundial, CIA The World Factbook. Disponível em: <http://www.suapesquisa.com/geografia/economia brasileira.htm $>$. Acesso em: 2 jul. 2016.

3. Para mais detalhes consultar o blog Auditoria Cidadá da Dívida e ver pesquisas de Maria Lucia Fattorelli. Disponível em: shttp://www.auditoriacidada.org.br/>. Acesso em: 20 ago. 2016.

4. Fonte: Portal da Transparência da União, jul. 2015.

5. Disponível em: $\leq$ http://correiodobrasil.com.br/populacao-do-brasil-chega-a-1952-milhoes-mulheres-sao-maioria/518660/\#.UF2dD411Qz4>. Acesso em: 2 out. 2012. 
6. PNAD-IBGE 2016, em 19 de maio de 2016, "a taxa de desemprego entre a população que está entrando no mercado de trabalho, de 18 a 24 anos, foi de $24,1 \%$ no primeiro trimestre de 2016". Disponível em: shttp://economia.uol.com.br/empregos-e-carreiras/noticias/redacao/2016/05/19/desemprego-entre-os-jovens-de-ate-24-anos-chega-a-241-diz-ibge.htm>. Acesso em: 14 dez. 2016.

7. A exemplo da rede estadual do Rio de Janeiro que possui várias parcerias com empresas: Grupo Thyssenkrup S/A, Grupo Pão de Açúcar, Lojas Americanas, Embratel, Oi futuro, Procter \& Gamble, entre outras. E vários tipos de projetos como o Dupla Escola e o Ensino Médio Inovador "voltado para o desenvolvimento de inovaçôes curriculares [...]. Compreende uma nova organização do Ensino Médio com a possibilidade de escolha pelo aluno do seu percurso formativo". Disponível em: <http://www.ri.gov.br/web/seeduc/exibeconteudo?article-id=1790845>. Acesso em: 17 dez. 2016.

8. Programa Autonomia da Fundaçáo Roberto Marinho adotado pela Rede Estadual do Rio de Janeiro e em vários outros estados.

9. Segundo o site da Secretaria Estadual de Educação do Rio de Janeiro: "O Programa Dupla Escola tem como objetivo transformar a unidade escolar convencional em um espaço de oportunidade para o aluno [...]. Dupla Escola significa duas vezes escola: jornada dupla [e] formação profissional, que o capacitem para o mercado de trabalho. Disponível em: <http://www.rj.gov.br/web/seeduc/exibeconteudo?article-id=1149929>. Acesso em: $17 \mathrm{dez}$. 2016. Ainda tem o Escola Aberta, que "busca repensar a instituição escolar como espaço alternativo para o desenvolvimento de atividades de formação, cultura, esporte e lazer para os alunos da educação básica das escolas públicas e suas comunidades nos finais de semana. Disponível em: <http://www.ri.gov.br/web/seeduc/exibeconteudo?article-id=1790831>. Acesso em: $17 \mathrm{dez} .2016$.

10.Essa proposta é fruto da rede NetFWD (Net Forward), fórum internacional organizado pela OCDE que reúne institutos e fundaçôes "capazes de inspirar propostas inovadoras para a atuação social privada com foco no desenvolvimento em todo o mundo". O IAS foi a única organização brasileira participante do grupo fundador. O objetivo da rede é "trocar experiências num momento em que também os países ricos buscam soluçôes para problemas sociais gerados pela crise financeira internacional (GIFE, 2012).

11. BIRD. Desenvolvimento e Redução da Pobreza: reflexão e perspectiva (preparado para as reunióes Anuais de 2004 do Banco Mundial e do Fundo Monetário Internacional). Outubro de 2004 (p. 5).

12. A pesquisa Soares Neto et al., "Uma escala para medir a infraestrutura escolar", com base no Censo Escolar de 2011 e em 194.932 escolas, constatou que apenas 0,6\% das escolas brasileiras têm infraestrutura próxima ao padrão mínimo para escolarização: biblioteca, laboratório de informática, quadra esportiva, laboratório de ciências e dependências adequadas para atender estudantes com necessidades especiais e básicas. E que somente 44\% contam com água encanada, sanitário, energia elétrica, esgoto e cozinha em sua infraestrutura (apud COLEMARX, s/d., p. 26). 


\section{Referências}

BANCO INTERNACIONAL PARA RECONSTRUÇÃO E DESENVOLVIMENTO (BIRD). Estratégia 2020 para a Educação. Aprendizagem para Todos. Washington, D.C.: Grupo Banco Mundial, 2011.

. Retomando o caminho para a inclusão, o crescimento e a sustentabilidade. Brasil diagnóstico sistemático de país. Sumário executivo. Brasília: Grupo Banco Mundial/Unidade Gerencial do Brasil, 2016.

BARROSO, S. O desenvolvimento travado. Jornal dos Economistas, n. 329, dez. 2016. p. 9-10.

BRASIL. Censo Escolar da Educação Básica 2012. Resumo Técnico. Brasília: INEP, 2013a. Disponível em: shttp://download.inep.gov.br/educacao basica/censo escolar/resumos tecnicos/resumo tecnico censo educacao basica 2012.pdf>. Acesso em: 8 maio 2017.

. Censo Escolar INEP 2015. Brasília: INEP, 2016. Disponível em: $\leq$ http://www. deolhonosplanos.org.br/censo-escolar-2015-confira-os-dados-disponibilizados-pelo-mecsobre-a-educacao-basica-no-pais/>. Acesso em: 03 maio 2017.

. Diretrizes Curriculares Nacionais Gerais da Educação Básica. Brasília: Ministério da Educação; Secretaria de Educação Básica; Diretoria de Currículos e Educação Integral, $2013 \mathrm{~b}$.

. Número de matrículas na educação básica por dependência administrativa. Brasil 2008/2014. Brasília: MEC, 2015a. Disponível em: <http://portal.mec.gov.br/index.php? option=com docman\&view=download \&alias=17044-dados-censo-2015-11-02-materia \&Itemid=30192>. Acesso em: 14 dez. 2016.

. Pesquisa Nacional por Amostra de Domicílios. Sintese de Indicadores 2012. Brasília: IBGE, 2012 Disponível em: <http://www.ibge.gov.br/home/estatistica/populacao/ trabalhoerendimento/pnad2012/default sintese.shtm $>$. Acesso em: maio de 2016.

Pesquisa Nacional por Amostra de Domicilios. Sintese de Indicadores 2015. Brasília: IBGE, 2015b. Disponível em: <http://www.ibge.gov.br/home/estatistica/populacao/ trabalhoerendimento/pnad2015/default sintese.shtm>. Acesso em: maio 2016.

COLEMARX. Plano Nacional de Educação 2011-2020: notas críticas. Rio de Janeiro: ADUFRJ, s/d.

.Sociedade de classes e subdesenvolvimento. 4. ed. Rio de Janeiro: Zahar, 1981.

FRIGOTTO, G. (Org.) Escola “sem” partido: uma esfinge que ameaça a educação e a sociedade. Rio de Janeiro: LPP, 2017. (no prelo).

GRUPO DE INSTITUTOS, FUNDAÇÓES E EMPRESAS (GIFE). Instituto Ayrton Senna integra fórum da OCDE de politicas para o desenvolvimento. 2012. Disponível em: $\leq$ http://gife.org.br/instituto-ayrton-senna-integra-forum-da-ocde-de-politicas-para-odesenvolvimento/>. Acesso em: 21 out. 2012.

HAYEK, F. Direito, legislação e liberdade: uma nova formulação dos princípios liberais de justiça e economia política. São Paulo: Visão, 1985. 
IAMAMOTO, M. A questão social no capitalismo. Revista Temporalis, Brasília, 2. ed., ano II, n. 3, p. 9-32, 2004.

JUNIA, R. Pronatec: nova fase, velhas contradiçôes. Rio de Janeiro: EPSJV: Fiocruz, 2016. Disponível em: <http://www.epsjv.fiocruz.br/index.php?Area=Noticia\&Num=1028>. Acesso em: $1 .^{\circ}$ abr. 2016.

MOTTA, V. Educação como caminho, mas qual? Todos pela Educação ou em Defesa da Escola Pública. In: BERTUSSI, T.; OURIQUES, N. (Orgs.). Anuário Educativo Brasileiro: visão retrospectiva. São Paulo: Cortez, 2011.

. Ideologia do Capital Social: atribuindo uma face mais humana ao capital. Rio de Janeiro: EDUERJ/FAPERJ, 2012.

POCHMANN, M. Comunicado IPEA n. ${ }^{\circ}$ 104. Brasília: Ipea, 2011.

REVISTA POLI. Radar dos Técnicos. Públicos Prioritários no Pronatec. Revista POLI: Saúde, Educação e Trabalho, Rio de Janeiro, ano IX, n. 48, p. 5, nov./dez. 2016.

Recebido em 04 de março de 2017. Aprovado em 13 de abril de 2017. 